\title{
TRAUMATIC LUNG INJURY- A MEDICOLEGAL PERSPECTIVE
}

\author{
Thankamma P. George1 , C. S. Sreedevi², Vitni Fernz ${ }^{3}$
}

${ }_{1}^{1}$ Associate Professor, Department of Forensic Medicine, Medical College, Trivandrum, Kerala, India.

2Professor, Department of Forensic Medicine, T. D. Medical College, Alappuzha, Kerala, India.

3 Junior Resident, Department of Forensic Medicine, Medical College, Trivandrum, Kerala, India.

\section{BACKGROUND}

ABSTRACT

Injuries of the chest causing disruption of the thoracic cage and damage to the lungs are increasing daily. Lungs may be injured due to blunt trauma like blows, compression of chest or grinding force of automobile run over or due to penetrating injuries by cutting and stabbing weapons, and projectiles from fire arm.

\section{METHODS}

In this study we analysed the pattern of injury to lungs and the socio-demographic pattern of the victims in trauma. 250 cases brought to a tertiary care institution for autopsy were studied from $1^{\text {st }}$ January 2005 to $30^{\text {th }}$ November 2005 (1 ${ }^{\text {st }} J u l y ~ 2005-30^{\text {th }}$ November prospectively, and 1st January-30th June 2005, retrospectively). A cross sectional study design including all cases of trauma to the thorax and heart with consecutive sampling was done. Data was collected in pro forma and analysed.

\section{RESULTS}

206 victims were males. Commonest cause of chest injury was trauma. 130 (52\%) were victims of road traffic accidents (Table 2 , Figure 1) and the vehicle implicated the most was bus (41 cases, $16.4 \%$, Table 3, Figure 2). Pedestrians constituted the majority (26.4\%). 70.6\% belonged to the working age group (21-60 years). 104 (41.6\%) were brought dead to the hospital. External injuries were not found in 67 cases (26.8\%). 107 cases (42.8\%) reported with lung injuries. Among the lung injuries 101 (93.5\%) were due to blunt impact and remaining $6(5.6 \%)$ were due to penetrating injuries. Haemothorax was observed in 102 cases on right side and 94 cases on the left side. 10 cases (4\%) of bronchial or tracheal ruptures with 7 cases of severance and 3 incidences of tear were recorded. Laceration was the common injury to both right and left lung, followed by contusion associated with rib fracture. Back aspect was the most commonly affected.

\section{CONCLUSIONS}

Death is an irreversible cessation of life and the medical and legal implications to its cause are obvious. From a medico-legal view point, cause of death is of prime significance for the forensic pathologist, legal justice system, and law enforcing agencies. Often the multiplicity of injuries leads to confusion in interpretation of physical signs, consequently delaying the accuracy of diagnosis and leading to subsequent medico-legal issues. ${ }^{19}$ Insurance policy claims, benefits for accidental deaths, personal injury litigation, and ultimate disposition of criminal charges may hinge upon the conclusions of the forensic pathologist.20 Among the 250 cases with thoracic injuries, $212(84.8 \%)$ were due to accidents. This is obviously due to technological advances and man's quest and fascination with modern high-speed vehicles and advancement in the industrial sector. ${ }^{21}$ Law enforcement agencies and democratic institutions need to address the social menace of homicidal and suicidal deaths. ${ }^{22}$

\section{KEY WORDS}

Lung Injury, Laceration, Chest, Trauma, Death

HOW TO CITE THIS ARTICLE: George TP, Sreedevi CS, Fernz V. Traumatic lung injury- a medicolegal perspective. J. Evolution Med. Dent. Sci. 2019;8(26):2131-2136, DOI: 10.14260/jemds/2019/468

\section{BACKGROUND}

The frequency of man-made disasters is fast increasing in the present era. Trauma to the chest challenges the integrity and even the viability of the entire individual. Unfortunately, thoracic trauma is a serious matter, not only in terms of the individual patient, but also in terms of the numbers affected, since injuries to thorax are common and are mostly attributable to road traffic accidents.

'Financial or Other Competing Interest': None.

Submission 22-04-2019, Peer Review 14-06-2019,

Acceptance 20-06-2019, Published 01-07-2019.

Corresponding Author:

Dr. Vitni Fernz,

Krishnasree, TC81/4418/1,

Thoppi Lane, Vanchyoor,

Trivandrum-695035, Kerala, India.

E-mail: vitnifernz@gmail.com

DOI: $10.14260 /$ jemds $/ 2019 / 468$

\section{(c) $(1) \odot$}

The bony thoracic cage contains the vital organs of circulation and respiration. On either side of thoracic cage is the pleural cavity, which are almost completely filled by the lungs. Each lung is covered with pulmonary pleura or visceral pleura, which is continuous at the root of lung with parietal pleura.

Between these two is the pleural cavity which contains a small quantity of thin serous pleural fluid. ${ }^{1}$ Each lung lies free in its own pleural cavity, attached to the mediastinum by its root. Right lung weighs $600 \mathrm{gm}$ and left lung $550 \mathrm{gm}$ approximately in healthy adult 1 . Statistical data analysis done on the weights of right and left lungs (For both male and female) from the autopsy studies by the Department of Forensic Medicine, Government Medical College Thiruvananthapuram revealed that the weight of right lung in males is approximately $422 \mathrm{gm}$ and $322 \mathrm{gm}$ for females and that of left lung, $381 \mathrm{gm}$ and $256 \mathrm{gm}$ in males and females respectively. Lungs are connected to the trachea by the 
branching system of bronchi and bronchioles. All structures which enter and leave the lungs through its root, which is enclosed in a short tubular sheath of pleura and each root consists of the principal bronchus, a pulmonary artery, superior and inferior pulmonary veins, lymph vessels and nodes, bronchial arteries and veins and the pulmonary plexus. $^{1}$

From the trachea, a principal bronchus passes to the hilus of each lung. The bronchi divide in to a tree like fashion within the lung. Each principal bronchus divides in to secondary, lobar bronchi (Two on left, three on right) to the lobes of the lung. Each lobar bronchus divides in to tertiary branches (Segmental bronchi) which supply the bronchopulmonary segments.

Chest injuries can be divided in to two groups. (1) Nonpenetrating (Closed chest injuries) and (2) penetrating (Open chest injuries).2,3 Injuries to soft tissues of the chest wall include abrasions, contusions, lacerations, incised wounds, penetrating wounds, haematoma etc. 4

Lungs may be injured due to blunt trauma like blows, compression of chest or grinding force of automobile run over or due to penetrating injuries by cutting and stabbing weapons, and projectiles from fire arm. ${ }^{5}$ High explosive blast act rapidly and severely as an external trauma and lungs will show evidence of congestion, haemorrhage and bullae.5,6

Blunt injuries to the lungs by blows from a blunt weapon, compression of chest or grinding force of a wheel running over the chest can produce various injuries with or without fracturing the ribs or showing any external injury. It may cause instantaneous death or may result in pleurisy, traumatic pneumothorax, haemothorax, air embolism or pneumonia. 6 Pulmonary contusion is a concessive loss of vessel integrity resulting in intraparenchymal and alveolar haemorrhage, with resulting decreased pulmonary compliance, ${ }^{7}$ and is the most common potentially lethal chest injury. Accidental blows to the chest, especially in automobile accidents, commonly cause bruising of the lungs. ${ }^{6}$ Pulmonary contusion is usually produced by severe blunt trauma and is encountered most frequently in association with rib fracture ${ }^{7}$ and also by sudden compression of the chest etc. e.g. from blows or from crush injuries. ${ }^{8}$ In all such blunt impacts all parts of the lung is suddenly and violently compressed, and the lung may be bruised or even ruptured.

Pulmonary contusions may be caused by direct violence, by contrecoup injury and by pincer forces. ${ }^{9}$ They appear as single or multiple haemorrhagic zones in the lung tissue or horizontal bruise corresponding to rib marks. They usually resolve over a period of days to weeks. In some instances, they may lead to diffuse interstitial pulmonary oedema and the so-called adult respiratory distress syndrome. ${ }^{9}$ Occasionally the contused lung may become infected and form a lung abscess. ${ }^{9}$ Transverse tears of the lung are associated with tearing of the parietal pleura and intercostal muscles for the sixth to the ninth interspace. In these cases, the lower ribs are forced forwards by severe violence applied to the back of the chest, inflicting a long elliptical tear on the parietal pleura and muscle of the affected interspace parallel with the ribs and at the same time tearing the lung transversely. ${ }^{7}$

The lungs are lacerated by rib fragments either when a segment of the chest has been bent in or when separate sharp pointed fragments are forced forwards from the posterior part of the chest. Here, the lateral surface of the lung is the principal target; lesions are distinguished by the fact that each rib leaves its own separate mark as three or four stellate lacerations in a row, almost equally spaced. This can result in internal haemorrhage, pneumothorax or septic infection. ${ }^{7}$ In cases of violent crushing impact, the pulmonary injury is often only one feature of extensive trauma, and the inwardly driven end of a broken rib may also damage the heart, any of the great thoracic vessels, the liver, the kidneys or the stomach. ${ }^{6}$ Laceration of the lung can occur even in blunt injuries, and vessels in the hilum (Especially pulmonary veins), or those more peripherally may be ripped, causing severe intrapleural or mediastinal haemorrhage. In children, lung injuries can occur without fracturing the ribs, because of the greater elasticity of the latter and the ability of the chest wall to deform. ${ }^{10}$ Even though there has been great displacement of the broken end of a rib at the moment of fracture, the bone usually returns to an approximately normal position immediately thereafter, so the observation of lack of displacement at the time of a later examination does not preclude the possibility of a previous displacement. 6 Lacerations of the lungs which communicate with a bronchus of any size give rise to an effusion of air in to the chest. If the parietal pleura is torn, air will be forced in to the tissues of the chest wall producing the crepitant distention of the subcutaneous tissue of face, neck, and chest, called subcutaneous emphysema. ${ }^{6}$

Penetrating injuries are produced either by sharp instruments (Stab wounds) or missiles (Gunshot wounds) ${ }^{9}$ and are commonly from stabbing by knives. The wounds may end in the lung parenchyma or in large vessels, or may be through-and-through injuries that emerge to cause further damage to the heart or great vessels. 10

There are three main differences between pulmonary injuries due to penetrating wounds of the chest wall, and those due to broken ribs. The former is more susceptible to infection, more extensive, and associated pneumothorax is frequently non-compressive. ${ }^{6}$ The broken ends of the rib is clean, although it may establish a bronchopleural fistula and is less likely to cause gross contamination in the pleural cavity than a knife or a bullet. Whatever be the cause of injury to the lung, it is likely to heal promptly unless repair is interfered with by infection, excessive haemorrhage or infarction. A clean incision of lung tissue usually heals quickly and the residual scar is apt to be small. ${ }^{6}$

Stab wounds involving the lung are very common ${ }^{11}$ and usually cause death by haemorrhage which may be slow or rapid depending on the size of the pulmonary vessel penetrated.

The high velocity bullet causes respiratory insufficiency by forming shock waves as massive energy is dissipated in the tissues, causing damage some distance away from the bullet tract, so that even if the bullet penetrates just one lung, the second may be just as badly damaged. ${ }^{12}$ If the pulmonary artery or vein is perforated, the individual will bleed profusely in to the chest cavity and death will occur in a few minutes. On the other hand, the wound may not penetrate a large vessel and only slight bleeding results, so that the victim may be able to move for a considerable distance, after being shot.7

Pneumothorax is an air collection in the pleural cavity. The incidence of pneumothorax is $30 \%$. There are three 
types, namely simple, open and closed pneumothorax. ${ }^{13}$ Pneumothorax may be caused by penetrating or blunt trauma, or iatrogenically during thoracocentesis, subclavian vein catheterization or percutaneous pleural or lung biopsy. ${ }^{9}$ The immediate effect of a pneumothorax is collapse of lung. ${ }^{14}$

A tension pneumothorax develops when a "one-wayvalve" air leak occurs either from the lung or through the chest wall. Air is forced in to the thoracic cavity without any means of escape, completely collapsing the affected lung. The mediastinum is displaced to opposite side, decreasing venous return and compressing the opposite lung. ${ }^{13,15}$

Haemothorax is a collection of blood in the pleural cavity and may be due to injuries of the chest wall, the lungs, the pulmonary vasculature, the heart or the major vessels. Massive haemothorax results from a rapid accumulation of more than $1500 \mathrm{ml}$ of blood in the chest cavity. It is most commonly caused by penetrating wound that disrupts the systemic or hilar vessels, 15 and is often associated with pneumothorax.6,13 Haemothorax is the rule in thoracic injury. ${ }^{6}$

Pneumonia may result from direct mechanical injury of the chest or may develop as a complication of an injury elsewhere in the body. The proportion of all cases of pneumonia attributed to trauma varies with different observers from 0.13 to 4.4 percent. 16 The pneumonias which are undoubtedly secondary to trauma are ordinary hypostatic pneumonias, the inhalation pneumonias associated with injuries of the upper airways and mouth such as compound fractures of the jaw bones and septic infections carries to the lungs by the blood from traumatic lesions elsewhere. Other lung infections should not be considered as traumatic unless there is strong evidence to substantiate the contention. ${ }^{7}$

\section{Primary Objective}

To describe the pattern or profile of lung injury.

\section{Secondary Objectives}

1. To evaluate the nature and intensity of the injuries of lungs with a view to find the cause of death.

2. To analyse the medicolegal aspects of lung injuries.

\section{METHODS}

This study is part of a larger study including 250 cases of trauma to chest, which aimed at analysing the pattern of injuries sustained to thorax following various types of trauma, with special reference to lung injury. 250 known dead bodies of both sexes with thoracic injuries brought for medicolegal autopsies to the mortuary of the Department of Forensic Medicine in a tertiary care institution were included in the present study. All cases from $1^{\text {st }}$ July 2005 till $30^{\text {th }}$ November were selected prospectively and from $1^{\text {st }}$ January till 30th June 2005, retrospectively. Among the 250 cases, 107 were found to have lung injuries and have been included in this study. Cross sectional design was followed.

A meticulous external examination was made, and details were entered in a proforma. From the autopsy records, the relevant details were retrieved: date of death, age and sex of the victim, height and weight of the body. The present investigation included the nature, dimensions and exact site of the injury. Autopsy was conducted by modified Rokitansky's method of in situ dissection in part and en masse removal. As in any medicolegal autopsy, this was done as follows. The skin of the chest wall was reflected on both sides as flaps by cutting through the chest muscles, leaving the ribs bare. In cases of suspected pneumothorax, the skin flap was reflected up to the axilla, creating a pocket, which was filled with water and chest wall punctured through one of the inter-costal spaces underwater with a scalpel so that air bubbles through if pneumothorax is present. The rib cage was examined for the presence of trauma, its extent and location. The thoracic cavity was then opened by cutting through cartilaginous portions of the ribs using a cartilage knife. The second rib was divided first, about $1 \mathrm{~cm}$ lateral to sternum, and then the line of cut extended downwards by cutting the cartilaginous portions of the ribs close to the costochondral junctions. The sternum was lifted up from the mediastinum, but the sternoclavicular joints and first ribs were left intact at this stage. Pleural cavities were examined for the presence of blood or other fluids. The pericardial cavity was also examined. The sternum was retracted anteriorly towards the head to exert tension and the joints were cut by a knife from the posterior aspect, removing the sterna plate. Then, both first ribs were cut. The thoracic and abdominal organs were removed en masse. ${ }^{13}$

All thoracic organs were examined for injury and when present, details like nature of injury, locations and dimensions were recorded. The injuries to the lungs and respiratory passages were studied meticulously and recorded. Attempt was made to correlate the external injuries with the internal injuries. Photographs were taken wherever possible.

\section{Statistical Analysis}

Data collected from the autopsy studies using the appended pro forma were entered and analysed using SPSS software.

\section{RESULTS}

It was observed that males constituted the majority of victims $206(82.4 \%)$. The commonest age group involved was 51-60 years $(20.8 \%)$, followed by $41-50$ years $(20 \%)$. The survival of a victim after sustaining injury varied from spot death to about four months. 104 victims were brought dead (41.6\%). Among the survivors, 72 (28.8\%), died within 6 hours of incidence and $37(14.8 \%)$ survived more than $60 \mathrm{hrs}$. Out of 250 cases investigated, there was no external injuries in 67 (26.8\%), abrasions alone were noted in 85 (34\%), contusions alone in $33(13.2 \%)$, laceration alone in $1(0.4 \%)$ and combination of various injuries in 64 (25.6\%) and 67(26.8\%) had no external injuries. Subcutaneous emphysema was noted in 14 (5.6\%), of which 13 were due to blunt trauma and 1 was due to penetrating injury. Majority of thoracic injuries were non-penetrating (95.6\%), out of which maximum number (52\%) was due to vehicular accidents. Majority of the victims of vehicular accidents sustaining thoracic trauma were pedestrians (26.4\%).

Involvement of air passage was observed in 10 cases, with rupture contributing to $7(70 \%)$ and tear to $3(30 \%)$ (Table 1).

Injury to the lung was noted in 107 cases (42.8\%), most commonly in traffic accidents $(60 ; 56 \%)$ Injuries were distributed among pedestrians - 17 cases (28.3\%), motorcyclists -15 cases $(25 \%)$, run over - 14 cases $(23.3 \%)$, occupants -5 cases $(8.3 \%)$, pillion riders -4 cases $(6.6 \%)$, 
pedal cyclists - 3 cases (5\%), drivers - 2 cases $(3.3 \%)$ in descending order of frequency. Other blunt trauma injuring the lung were fall from heights - 18 cases $(16.8 \%)$, rail traffic accidents - 15 cases (14\%), fall of heavy objects on the body and stab wounds - 6 cases (5.6\%) each and catamaran accidents -2 cases $(1.8 \%)$ (Table 2 ).

Blunt impact caused lung trauma in 101 cases (93.5\%) and penetrating impact, in $6(5.6 \%)$ cases. Right lung was injured in $81(75.7 \%)$ cases and the left in 60 (56\%) cases. Among the blunt impact, right lung alone was involved in 47 (43.9\%), the left lung alone in $22(20.6 \%)$, and bilateral involvement in 32 (29.9\%). Penetrating injuries were noted in left lung alone in $5(4.7 \%)$ (Table 5), right lung alone in 1 (1\%) and bilateral in a single case (1\%) (Figure 1); 4 cases in the left side were due to transfixing injuries, one case involving the right was a punctured wound and the remaining was an incised wound. Out of the right lung injuries, whole lobes were involved in 23 cases (21.5\%), followed by upper and middle lobes in 20 (18.7\%). Penetrating injuries involved the middle and lower lobes in one case each (Fig. 1, Table 4).

Laceration was the commonest type of lung injury, involving 97(90.7\%) cases among which right lung was injured in 55 (56.7\%) cases and the left in 42 (43.3\%) cases. Contusion was seen in 21 (19.6\%) cases (Right side 12 cases and left side 9 cases). Right lung was affected by incised and punctured wound (One case each) and on left side lung was found transfixed in 4 cases and punctured in 1 case. Combination of contusion and laceration were seen in 13 cases, 10 on the right side and 3 on the left side. Avulsion of lung was seen in 3 cases ( 2 on the right and one on the left) (Tables 4,5 ). Commonest injury to left lung was laceration in $42(76.4 \%)$, followed by contusion in $9(16.36 \%)$, transfixing wound in $4(7.27 \%)$, punctured wound in $2(3.6 \%)$ and crushing injury in $1(1.8 \%)$ (Table 5$)$.

Punctured wound and incised injury were seen in one case $(0.9 \%)$ each on middle and lower lobe of right lung and upper lobe in $3(2.8 \%)$ cases and lower lobe in $2(1.8 \%)$ cases on the left lung.

All lobes of lungs were involved in 49 cases (45.7\%), 23 (21.5\%) involving the right and 26 (24.3\%) involving the left (Figure 1). Upper lobes alone were involved in 17 (16\%) cases on the right side and 22(20.5\%) cases on the left. In left lung, both lobes were affected in 26 (10.4\%), the upper lobe alone in 22 (8.8\%) and lower lobe alone in 12 (4.8\%) and the back aspect was affected in 37 cases (46.8\%) and multiple sites were involved in 19 cases (24.05\%). In right lung also the back aspect was injured in majority, i.e., 37 (46.8\%), followed by multiple sites in 19 (24.05\%). In the left lung the lowest incidence of 1 each (1.6\%) was in inner aspect, front and outer aspect, hilum and outer aspect and back and front aspect.

Lung injuries were associated with rib fractures in 101 $(40.4 \%)$ cases of blunt trauma and $6(5.6 \%)$ cases of penetrating trauma. In $6(6.6 \%)$ cases there were lung injuries in the absence of thoracic injuries. Out of 76 cases of rib fracture on right side alone, 29 (38.2\%) showed no corresponding injury on the lung and 47 (61.8\%) showed right lung injury (Table 3 ). Out of 51 cases with rib fracture on left side alone, 22(43\%) showed corresponding lung injury (Figure 2). Among 103 with bilateral rib fracture, 32 (31.1\%) showed corresponding lung injury. It was noted that the right lung showed injury to the whole lobe in 23 cases (28.4\%), followed by upper \& middle lobes 20 (8\%), and upper lobe alone 17 (6.8\%).

$51(20.4 \%)$ and $41(16.4 \%)$ cases each showed 150-300 $\mathrm{ml}$ of blood in the right and left chest cavities respectively. 22 (8.8\%) and 24 (9.6\%) cases each showed 301-750 $\mathrm{ml}$ of blood in the right and left chest cavities respectively (Figure 3).

\begin{tabular}{|c|c|c|c|c|c|}
\hline \multirow{2}{*}{ Injury } & \multirow{2}{*}{ Trachea } & \multicolumn{3}{|c|}{ Bronchus } & \multirow{2}{*}{ Total } \\
\cline { 3 - 5 } & & Right & Left & Bilateral & \\
\hline Tear & 3 & 0 & 0 & 0 & 3 \\
Rupture & 2 & 1 & 2 & 2 & 7 \\
\hline Total & $\mathbf{5}$ & $\mathbf{1}$ & $\mathbf{2}$ & $\mathbf{2}$ & $\mathbf{1 0}$ \\
\hline
\end{tabular}

Table 1. Distribution of Injuries to Trachea \& Bronchi

\begin{tabular}{|c|c|c|c|c|c|}
\hline Cause of Injury & $\begin{array}{c}\text { No. } \\
\text { Injury }\end{array}$ & Right & Left & Bilateral & $\begin{array}{c}\text { Total } \\
\text { Cases }\end{array}$ \\
\hline Traffic & 81 & 23 & 11 & 15 & 130 \\
Fall from height & 29 & 8 & 5 & 4 & 46 \\
Stab & 3 & 2 & 4 & 1 & 10 \\
Railway occurrence & 11 & 3 & 5 & 8 & 27 \\
Fall of heavy object & 5 & 2 & 0 & 4 & 11 \\
Fall from boat & 1 & 1 & 0 & 1 & 3 \\
CPR & 4 & 0 & 0 & 0 & 4 \\
Blow & 3 & 0 & 0 & 0 & 3 \\
Industrial accident & 1 & 0 & 0 & 0 & 1 \\
Run over (road) & 1 & 2 & 0 & 2 & 5 \\
Run over (rail) & 5 & 2 & 2 & 1 & 10 \\
\hline Total & $\mathbf{1 4 4}$ & $\mathbf{4 3}$ & $\mathbf{2 7}$ & $\mathbf{3 6}$ & $\mathbf{2 5 0}$ \\
\hline \% & 57.6 & 17.2 & 10.4 & 14.4 & 100 \\
\hline Table 2. Showing the Distribution of Causes of Injury to Lungs \\
\hline
\end{tabular}

\begin{tabular}{|c|c|c|c|c|c|}
\hline \multirow{2}{*}{ Rib Side } & \multicolumn{4}{|c|}{ Lung Side } & \multirow{2}{*}{ Total } \\
\cline { 2 - 5 } & No Injury & Right & Left & Bilateral & \\
\hline No Injury & 6 & 2 & 2 & 4 & 14 \\
Right & 52 & 20 & 1 & 3 & 76 \\
Left & 39 & 3 & 14 & 0 & 56 \\
Bilateral & 47 & 18 & 10 & 29 & 104 \\
\hline Total & $\mathbf{1 4 4}$ & $\mathbf{4 3}$ & $\mathbf{2 7}$ & $\mathbf{3 6}$ & $\mathbf{2 5 0}$ \\
\hline$\%$ & 57.6 & 17.2 & 10.8 & 14.4 & 100 \\
\hline Table 3. Showing Lung Injury Associated with Rib Injury \\
\hline
\end{tabular}

\begin{tabular}{|c|c|c|c|c|c|}
\hline \multirow{2}{*}{ Type of Injury } & \multicolumn{3}{|c|}{ Type of Force Exerted } & \multirow{2}{*}{ Total } \\
\cline { 2 - 5 } & Penetrating & $\begin{array}{c}\text { Blunt } \\
\text { Direct }\end{array}$ & $\begin{array}{c}\text { Blunt } \\
\text { Indirect }\end{array}$ & Tot \\
\hline No injury & 7 & 146 & 18 & 171 & 68.4 \\
Contusion & 2 & 10 & 0 & 12 & 4.8 \\
Laceration & 0 & 47 & 5 & 52 & 20.8 \\
Incised wound & 1 & 0 & 0 & 1 & 0.4 \\
Puncture wound & 1 & 0 & 0 & 1 & 0.4 \\
Contusion \& laceration & 0 & 8 & 2 & 10 & 4.0 \\
Avulsion \& lacerations & 0 & 1 & 0 & 1 & 0.4 \\
Crushing & 0 & 1 & 0 & 1 & 0.4 \\
Laceration \& lobectomy & 0 & 1 & 0 & 1 & 0.4 \\
\hline \multicolumn{7}{|c|}{$\mathbf{1 1}$} & $\mathbf{2 1 4}$ & $\mathbf{2 5}$ & $\mathbf{2 5 0}$ & $\mathbf{1 0 0}$ \\
\hline Table 4. Showing Injury to Right Lung and Type of Force Exerted \\
\hline
\end{tabular}

\begin{tabular}{|c|c|c|c|c|c|}
\hline \multirow[b]{2}{*}{ Type of Injury } & \multicolumn{3}{|c|}{ Type of Force Exerted } & \multirow[b]{2}{*}{ Total } & \multirow[b]{2}{*}{$\%$} \\
\hline & Penetrating & $\begin{array}{c}\text { Blunt } \\
\text { Direct }\end{array}$ & $\begin{array}{c}\text { Blunt } \\
\text { Indirect }\end{array}$ & & \\
\hline No injury & 6 & 164 & 19 & 189 & 75.6 \\
\hline Contusion & 0 & 8 & 1 & 9 & 3.6 \\
\hline Laceration & 1 & 36 & 5 & 42 & 16.8 \\
\hline Puncture wound & 2 & 0 & 0 & 2 & 0.8 \\
\hline Transfixing wound & 2 & 2 & 0 & 4 & 1.6 \\
\hline Contusion \& laceration & 0 & 3 & 0 & 3 & 1.2 \\
\hline Crushing & 0 & 1 & 0 & 1 & 0.4 \\
\hline Total & 11 & 214 & 25 & 250 & 100 \\
\hline
\end{tabular}



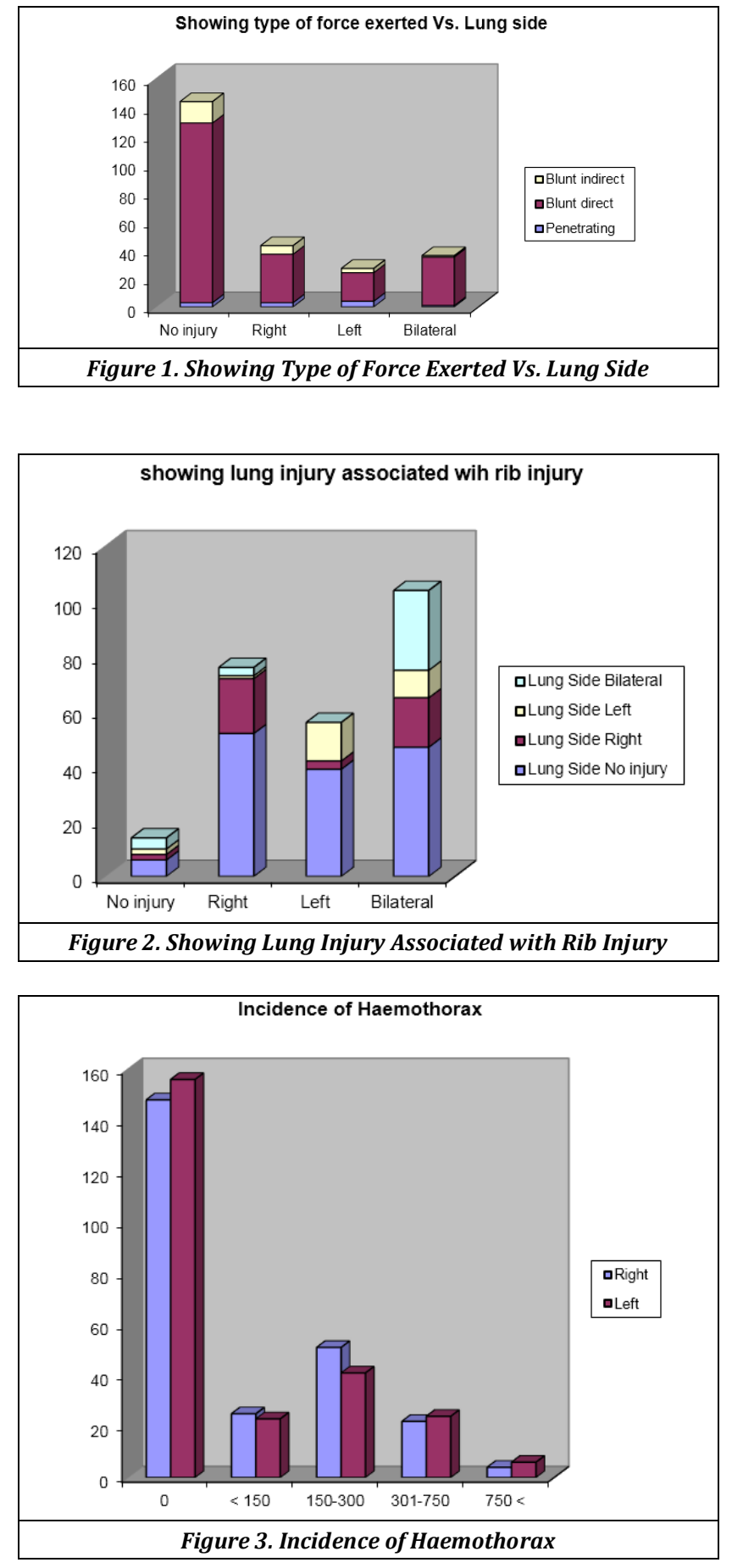

\section{DISCUSSION}

Thoracic injuries are one of the important causes of mortality in accidents. Its incidence is fast increasing due to various factors relating to modern civilization and globalization. The dominance of males among victims is readily explainable by the fact that males are more exposed to hazards of roads, industry, violence and sports.

Bronchial or tracheal ruptures are rare consequences of blunt injury and we observed 10 (4\%), 7 with rupture and 3 with tear; most were associated with fractures of first three ribs is in agreement with Di Maio, Vincent. ${ }^{9}$ Lung trauma is an important component of thoracic injuries.

Out of 250 cases investigated, 107 (42.8\%) had lung injuries. Among the lung injuries 101(94.3\%) were due to blunt impact, $6(5.6 \%)$ due to penetrating injuries. Sudeshini ${ }^{16}$ reported $74.14 \%$ with blunt trauma and $25.86 \%$ with penetrating injuries. 146 cases of traffic related trauma to chest showed lung injury in $60(41.1 \%)$. Lung injury was noted in $18(40.9 \%)$ out of 44 cases of fall from height. Of 9 incidences with stab injuries 6 (66.7\%) were noted with lung trauma. 76 cases showed rib fracture on right side, and 29 had no corresponding injury on the lung and in 47 cases right lung was injured. Of 51 cases with rib fracture on left side, only $22(43.1 \%)$ showed corresponding lung injury. Out of 103 cases with bilateral rib fracture only 32 (31\%) cases showed corresponding lung injury a probable explanation could be that usually a simple fracture of the rib will neither contuse nor lacerate the underlying lung. However if the impact of the chest is forceful enough to cause inward displacement of the fractured ends of the ribs they may puncture and lacerate the underlying pleura and lung (Di Maio, Vincent) ${ }^{9}$ also in children, lung injuries can occur without fracturing of ribs, because of the greater elasticity of the latter and the ability of chest wall to deform (Bernard Knight). ${ }^{14}$

Injury to the right lung reveals that injury to the whole lung constituted 23 cases (29.1\%), followed by upper \& middle lobes in 20 (25.3\%), upper lobe alone in 17 (21.5\%). Studies revealed that in case of left lung, both lobes were affected in 26 (42.6\%) victims, upper lobe alone in 23 $(37.7 \%)$, with a lower incidence in case of lower lobe 12 (19.7\%). Laceration was the commonest injury to the right lung in 55 victims (69.6\%), followed by contusion in 12 $(15.1 \%)$, combination of contusion and laceration in 10 cases (12.6\%).Of 250 cases, in 189 (75.6\%), the left lung was unaffected. Common type of injury was laceration in 42 (68.9 $\%$ ) followed by contusion in $9(14.8 \%)$, transfixing wound in $3(4.9 \%)$ with crush in 1 (1.6\%). A similar previous investigation by Sudeshini (1987) ${ }^{17}$ reported the general incidence of laceration in $41.86 \%$ and contusion $34.88 \%$.

Regarding site of injury to the right lung, majority 35 (44.3\%) were on the back aspect, followed by multiple sites in 19 (24.05\%). Back aspect was involved in left lung in 22 (36\%), followed by multiple sites in 18 (29.5\%), with 1 each (1.64\%) on inner aspect, front and outer aspect, hilum and outer aspect and back and front aspect. A probable explanation could be due to the countercoup effect as stated by Osborn. Haemothorax was observed in 102 on right side and 94 on the left side (Figure 3). Blood in pleural cavity remained in a fluid state, as observed by Wilson (Gordon \& Shapiro).

\section{CONCLUSIONS}

Death is an irreversible cessation of life and the medical and legal implications to its cause are obvious. From a medicolegal view point, cause of death is of prime significance for the forensic pathologist, legal justice system, and law enforcing agencies. Out of 250 cases investigated with injuries, in 202 $(80.8 \%)$, cause of death was due to injuries of chest and combinations of other regions. From a medico-legal standpoint, manner of death is of great importance. ${ }^{18}$ Often the multiplicity of injuries leads to confusion in interpretation of physical signs, consequently delaying the accuracy of diagnosis and leading to subsequent medico-legal issues. ${ }^{19}$ Insurance policy claims, benefits for accidental deaths, personal injury litigation, and ultimate disposition of criminal charges may hinge upon the conclusions of the forensic pathologist. ${ }^{20}$ Among the 250 cases with thoracic injuries, 
212 (84.8\%) were due to accidents. This is obviously due to technological advances and man's quest and fascination with modern high-speed vehicles and advancement in the industrial sector. ${ }^{21}$ Law enforcement agencies and democratic institutions need to address the social menace of homicidal and suicidal deaths. ${ }^{22}$

\section{REFERENCES}

[1] Reddy NKS. The essentials of forensic medicine and toxicology. 34th edn. Om Sai Graphers 2017.

[2] Gordon I, Shapiro HA. Forensic Medicine: a guide to principles. $2^{\text {nd }}$ edn. Edinburaugh: Churchill Livingstone 1982: p. 301-10.

[3] Mukherjee JB. Forensic medicine and toxicology. Vol. I. $2^{\text {nd }}$ edn. New Delhi: Accademic Publishers Culcutta 1985: p. 373-9.

[4] Guharaj PV, Chandran MR. Forensic Medicine. 2nd edn. Chennai: Orient Longman Pvt Ltd., 2003: p. 144-7.

[5] Vij K. Textbook of Forensic medicine and toxicology: principles and practice. $5^{\text {th }}$ edn. Elsevier India Publisher 2011: p. 290-2.

[6] Dutta AK. Essentials of Human Anatomy. Part 1: Thorax and Abdomen. 9th edn. Kolkata: Current Books International 2014.

[7] Ramanes GJ. Cunningham's Manual of Practical Anatomy. Thorax \& Abdomen. Vol. 1. 15th edn. Oxford Medical Publications 1998: p. 1-82.

[8] Williams PL, Warwick R. Gray's Anatomy. 36 th edn. Edinburg: Churchill Livingstone 1980: p. 286-92.

[9] Di Maio VJ, Di Maio D. Forensic Pathology. 2nd edn. New York: CRC Press 2000: p. 117-30.

[10] Prathapan V. Fall from height. Thesis submitted to the University of Kerala for MD (Forensic Medicine) Exam, 1994.

[11] Moyalan JA. Trauma \& Surgery. Philadelphia: JB Lippincott Company 1792: p. 77-195.
[12] Mant KA. Taylor's Principles and practice of medical jurisprudence. $13^{\text {th }}$ edn reprinted. Churchill Livingstone 2000: p. 228-32.

[13] Umadethan B. Practical Forensic Medicine: a guide to medico-legal practice. $2^{\text {nd }}$ edn. Thiruvananthapuram: R.V. Publications 1994: p. 172.

[14] Polson CJ, Gee DJ, Knight B. The Essentials of Forensic Medicine. $4^{\text {th }}$ edn. New York: Pergamon Press, Oxford 1985: p. 180-7.

[15] Tedeschi CG, Eckert WG, Tedeschi LG. Forensic Medicine: a study in trauma and environmental hazards. Mechanical trauma. Vol. 1. Philadelphia, PA: W.B. Saunders Company 1977: p. 199-208.

[16] Baron RM, Bartlett JG. Bronchiectasis and lung abscess. In: Longo DL, Fauci AS, Casper DL, et al. eds. Harrison's Principles of Internal Medicine. Vol. 2. 18th edn. New York: McGraw-Hill Medical 2012: p. 213041.

[17] Chellayan S. Study of medical aspects of injuries to thorax: Thesis submitted to the University of Kerala for MD (Forensic Medicine) Exam 1987.

[18] Geetha O. Pattern of injuries in victims of road traffic accidents thesis submitted to the University of Kerala for MD Forensic Med Exam 2001.

[19] American College of Surgeons Committee on Trauma: Advanced Trauma Life Support for Doctors, Student Course Manual. $6^{\text {th }}$ edn. ACS, 2003.

[20] Wilson JN. Watson-Jones - Fractures and joints injuries. Vol. 1. $6^{\text {th }}$ edn. Edinburgh, New York: Churchill Livingstone 1982: p. 137-206, 547.

[21] Moritz AR. The Pathology of Trauma. $2^{\text {nd }}$ edn. Lee \& Febiger 1954: p. 1-76, 133-222.

[22] Modi JP. Modi's Medical jurisprudence and toxicology. $25^{\text {th }}$ edn. Lexis Nexis Butterworths Publishing Company 2016. 